\title{
Analysis on the Collision and Conflict between the Administrative Power and the Academic Power in Colleges and Universities
}

\author{
Yuduo Wang \\ College of Communications, Beijing Information Science and Technology University, Beijing, China \\ wyd183_lg@163.com
}

Keywords: Higher education, Administrative management, Academic power, Collision and conflict

\begin{abstract}
It has been a common concern for higher education workers to establish a modern university system and reform the existing internal management system in colleges and universities according to the current situation and development trend of the higher education, so that the colleges and universities return to their essence. This article introduces the conflict between the administrative power and the academic power existing in colleges and universities and expounds the significance of coordinating the relationship between the academic power and the administrative power in promoting the development of colleges and universities. Finally, it proposes the measures to coordinate the academic power and the administrative power to ensure that the academic power is not interfered by the administrative power and it is independent so as to ensure the operation of colleges and universities in a healthy and orderly state.
\end{abstract}

\section{Introduction}

The power structure of colleges and universities in our country belongs to the pattern of administrative power. The more prominent fact is that the administrative power is obviously higher than the academic power, and there is a serious administrative phenomenon in the management of higher education institutions. This phenomenon itself has seriously hindered and restricted the development of colleges and universities. For example, the generalization of administrative power controls the academic power to a certain extent, which violates the nature and law of educational administration, and also affects the scientific management of schools; the expansion of the administrative power and the lack of independence and autonomy of the academic power limit the free space and creativity for academic growth; the centralization of administrative management has made power concentrated in the hands of a few, thus the opinions of most people are ignored, which results in the failure to achieve scientific and democratic management and decision-making; the traditional and single way of the administrative management based on the general use of administrative orders is unable to achieve public decision-making and democratic management, seriously affecting the improvement of a college and university's own management system and restricting or even hindering the development of them. On the other hand, the academic power of colleges and universities is gradually being weakened and marginalized, and even replaced by administrative power. The result is that the academic power of teachers is weakened, and scholars, professors, teachers and students are lack of voice and decision-making autonomy on academic issues, affecting the teachers' academic pursuit, management and decision-making. Thirdly, it brings about the problem of academic power itself. The control and regulation on the academic power caused by academic corruption has led to the virtual higher and false phenomenon in the academic power. Based on the academic supremacy of academic minorities and academic abuse of power, scholars propose to control the raise of the status of academic power in the management of colleges and universities, forming the tendency of curbing and weakening academic power. However, teachers and students are oppressed by the administrative power, and are lack of awareness and challenges of rights protection consciousness, afraid to voice personally or jointly, allowing the arbitrary execution of the administrative power by the administrative departments at 
the mercy.

\section{Purpose and significance of coordinating the relationship between the administrative power and the academic power}

The excessive administration of college and university management violates the essence and law of education management, which is manifested in the bureaucratization, authoritarian and homogenization of administrators. The disadvantages lie in the generalization of the administrative power. The operation of a college and university is not centered on talent training and academic research. Too much interference with academic power is the typical transgression and dislocation of administrative power.

To coordinate the relationship between the administrative power and the academic power is virtually the "de-administration" from the management of a college and university, so that higher education management can return to the essence and nature of a college and university. Instead of weakening the administrative power of internal administrative management in higher education institutions, the de-administrativeization requires the administrative management to return to its own nature and do a good job in its own service so that the academic power can exert its influence in the academic field when there are major issues such as academic development and policy-making, really playing the role in protecting academic freedom and everyone's academic power. The rational division of the academic power and the administrative power so as to separate the two from each other, cannot deny the role of the administrative power in the management of a college and university nor make the academic power and the administrative power opposite to each other, but to form a respectable basic boundary and category division, ensuring that the operation of the two powers are in line with their own laws.

We should actively explore a new management pattern for colleges and universities with the principle of "Professors Taking Charge of Academic Study" and "Expert Schooling". "Professors Taking Charge of Academic Study" is to let professors and scholars with prestige and prestige control the academic power of colleges and universities, allowing the academic power to fully play its role and value so as to truly guarantee the academic freedom. "Expert Schooling" refers to letting experts with managerial and practical abilities use their professional knowledge and rich management experience to carry out the management of the affairs in colleges and universities so as to ensure that both the administrative power and the academic power are neither inferior nor superior to each other.

\section{Collision and Conflict between the Academic Power and the Administrative Management}

Running the school well is the goal pursued by each college and university. However, it is not determined by the college and university themselves. In fact, to enable a college or university truly become a well-established and proficient school recognized by society, not only the joint efforts of all faculty and staff, but more importantly, an effective and scientific management mechanism is required.

\subsection{The administrative management should focus on service instead of management}

The academic level is the most important indicator in evaluating the schooling level of a college or university. No college or university at home and abroad is famous for its management level. The administrative management of colleges and universities refers to that a college or university adopts certain measures and means to mobilize various resources such as personal and property resources possessed by the schools, to achieve efficient, orderly and healthy operation, in order to complete their educational goals, relying on certain institutions and systems. In fact, to make the administrative management play its due role is a very important factor in running a university. The administrative management seems more important, but in essence, its role should be more reflected in the service. If colleges and universities do not regard academic pursuits as the main line, and all 
behaviors in schools are dominated by administration, the administrative management will result in the rigid management of the school, constraining the teachers. In this case, how can we talk about the academic pursuits or create a good academic atmosphere! Conversely, if a college or university is led by academic pursuits, the school's administrative management is to fully serve academic behaviors, and then the schooling level will progress naturally faster.

\subsection{The academic pursuit should focus on the level instead of the form}

The goal of a college or university is to cultivate qualified high-level talents on the other hand; and to carry out the exploration and pursuit of natural science so as to promote the development and progress of human science and technology on the other hand. For a higher education institution, the foundation of achieving the goal is undoubtedly the academic level of its teaching staff. However, just as Zhu Qingshi said: "Like the social evaluation system, our university evaluation system also means to award titles and give higher material remuneration and various kinds of treatment based on the number of articles and various awards. Each lesson needs a teacher to take seven or eight hours to prepare, but professors can teach fluently without having to prepare the lesson because they have taught for decades. Therefore, professors have no enthusiasm for the reform of the curriculum. "The realistic academic pursuit of colleges and universities has changed its nature. Due to the guiding factors like the evaluation system and other aspects, teachers have to pursue the number of papers, the amount of research advances, the number of patent applications, but pay less attention to the level and quality thereof. What is more, teachers' pursuit of administrative promotion has become a new trend in higher education institutions because they understand that administrative posts can lead to control of more resources.

\subsection{Unmatched reward and punishment mechanism}

It is understandable that the administrative management of colleges and universities is a powerful supervisor and executor of the normal operation of schools. However, if the administrative management cannot be correctly defined, it may become a drag or even an obstacle to the development of schools. People often can hear that some schools have teacher regulations, but we seldom hear they have regulations on the administrative personnel. Since the most prominent feature of teacher profession is that teachers are required to be a model of virtue for others, so the teachers can all abide by their professional ethics very well. Even without the teacher regulations, most teachers can be strict with themselves. We have to say that the promulgation of the teacher regulations has effectively promoted the standardization of teachers' teaching behaviors. However, the administrative management problems often occur in colleges and universities, and there is not any supervision and punishment mechanism for that. In fact, in such colleges and universities, the teachers seem to have become the most disadvantaged groups at the bottom. Students can judge their education, and the administration can criticize them as well. The teachers are bound by various rules, regulations and requirements. Therefore, the dominant position of teachers is ignored.

\section{Rectification Suggestions and Measures}

Facing the coordination between the academic power and the administrative management in universities at present, higher education workers must think about such a question: How to balance the two so that a college and university can run in a healthy and orderly state? In this regard, I have the following suggestions.

\subsection{To clearly define the administrative management in colleges and universities}

Due to the administrative nature of the existing college and university management and the legacy and spread of the "worship for officials" mentality, the administrative power far exceeds the academic power over the control and management of the school resources. Therefore, the serving subject and the served subject are often put on the cart before the horse, the administrative power is highly inflated, and even seriously opposite to the academic power. "Bureaucracy" prevails and 
academic affairs are handled administratively, making some originally normal work difficult to deal with. Therefore, the primary problem to be solved is to accurately define the administrative management and the academic management, clarify their respective functions, and the relationship between the administrative power and the academic power of colleges and universities clear, correcting the behaviors beyond power, wrong execution or lack of posts so that the administrative management can really play its serving role, the colleges and universities can operate in a correct way.

\subsection{To solve the issues of evaluation system and reward and punishment mechanism}

With the deepening of higher education reform, the evaluation system is gradually being improved. At present, many colleges or universities have established the highly-quantitative or all-quantitative evaluation index systems in teachers' evaluation. Compared with the qualitative evaluation, they have largely prevented or eliminated the interference of human factors, becoming relatively just and fair. However, how to formulate a scientific evaluation system is very important in the development and construction of colleges and universities. If the quantitative standard is too high, the teachers are likely to blindly pursue the quantity, not paying enough attention to the quality. For a college teacher, it is an integral part either for research or for teaching. At present, many colleges or universities attach equal importance to research and teaching on the surface, but as for the formulation of actual indicators, they tend to be more inclined to research. Furthermore, many universities also link the quantity of published papers and research achievements with the teachers' own economic interests directly, regarding the performance of research as the main indicators for a teacher's evaluation and promotion. On the other hand, we also need to solve the feedback and the reasonable application of the evaluation results. The purpose of evaluation is to provide the basis for the reward and punishment, appointment and promotion of teachers, so as to guide and motivate teachers to better fulfill their job responsibilities and improve the overall quality. The implementation of evaluation can not only mobilize the teachers' enthusiasm, but also conducive to the overall goals of the school and the fulfillment of various tasks. If in the actual evaluation, the evaluation results cannot be timely fed back and reasonably applied and the teacher's problems will not be solved timely, and the teachers with relatively outstanding performance cannot be given incentives promptly. In such circumstances, teachers are likely to have a slack mentality and negative psychological factor, which further affects the sustainable development of schools.

\subsection{To simultaneously define the punishment regulations on the administrative management}

Teachers are the main body of a university. They are naturally required to strictly perform their duties of teaching and educating, and regulate their own behaviors. In other words, if teachers violate the regulations, they should be punished accordingly. However, accountability can not only be on the front-line teachers, but also on the administrators. If there is no corresponding regulatory constraint against wrong performance of power, it is not unfair for a normally-operating higher education institution. Therefore, I believe that only the simultaneous development of administrative regulations and teacher regulations is the basic guarantee for the healthy operation of universities.

\subsection{To solve the problem of the administrative power pushing aside the academic power}

The traditional college or university was not an administrative department, but an academic body with the supremacy of academic power. The administrative personnel in the colleges and universities should not be "officials" but should be servicemen who should safeguard the normal operation of the schools. However, in our country, under the current situation, the colleges and universities are administrated by the government, which show a big difference from foreign universities where they perform the independent administration. The colleges and universities under the administrative management system have caused that the staff allocation, organization setup, operation mode and management concepts have a serious "official" atmosphere. Therefore, in the process of a college and university administration, the generalization of the administrative power leads to the shrinking of the academic power, and thus the academic power increasingly serves the 
administrative power. It is obviously reflected in that the front-line teachers' business appeals cannot be met, or the reasonable opinions of academic experts cannot be effectively adopted. On the other hand, due to the fact that the administrative power is in charge of more resources in schools and has more influence in various fields, a good academic atmosphere cannot be formed, thus excellent teachers cannot exert their due abilities, and the academic power of schools cannot be established naturally. Virtually, these have formed a serious obstacle to the development of the school.

\section{The improvement of the administrative management level is the need for the healthy development of colleges and universities}

With the development of society and economy and the progress of science and technology, both international competition and domestic competition are embodied in talent competition. As the base for personnel training, colleges and universities must be on the cusp of competition. Both the state and the society have higher requirements on colleges and universities, so the higher education institutions are bearing increasingly-heavier responsibilities. The administrative management level becomes one of the concrete manifestations of improving the competitiveness of colleges and universities. Therefore, to adapt to the development of society, colleges and universities must truly shoulder their own historical mission and must raise their administrative level. Only with scientific management, can colleges and universities be able to develop steadily and healthily.

\section{Conclusion}

The most important two aspects of running a college or university are the cultivation of talents and the construction of a modern university system. Of them, the most prominent issue is how to coordinate the relationship between the academic power and the administrative power. Colleges and universities must not only ensure the quality of talent training, but also form their own characteristics and reach high standards. For a healthy college or university, the relationship between the academic power and the administrative power must also be coordinated and reasonable. For a declining college or university, there must be unsatisfactory points in the relationship between the academic power and the administrative power. Speaking without exaggeration, coordinating the relationship between the academic power and the administrative power is the most basic guarantee for running a college or university well.

\section{Acknowledgement}

Thanks to the financial support from the "promoting the connotative development of colleges and universities - the quality of postgraduate education project -thinking and countermeasure research on first-level subject assessment " project of Beijing University of Information Science and Technology

\section{References}

[1] Zhu Qingshi. To restore the original academic pursuit of colleges and universities [J]. Shenzhen Special Zone Daily - Multimedia Digital Edition, May 2012.

[2] Yue Changhuan. Thoughts on the administration of Colleges and Universities [J]. Liaoning Education Research, 2007, (4). 